\title{
Functional Properties of Donor (Al) and Acceptor (Cu) Codoped High Dielectric Constant ZnO Nanoparticles
}

\author{
Huma Tariq and Fahad Azad \\ School of Natural Sciences (SNS), National University of Sciences and Technology (NUST), 44000 Islamabad, Pakistan \\ Correspondence should be addressed to Fahad Azad; fahad.azad@sns.nust.edu.pk
}

Received 9 September 2021; Revised 5 December 2021; Accepted 14 December 2021; Published 13 January 2022

Academic Editor: Sami-Ullah Rather

Copyright (c) 2022 Huma Tariq and Fahad Azad. This is an open access article distributed under the Creative Commons Attribution License, which permits unrestricted use, distribution, and reproduction in any medium, provided the original work is properly cited.

In this work, we have synthesized donor-acceptor $(\mathrm{Al}-\mathrm{Cu})$ codoped $\mathrm{ZnO}$ nanoparticles with a doping concentration of $0 \%, 0.25 \%$, $0.5 \%$, and $0.75 \%$ by coprecipitation method. The synthesized samples were then annealed at $350^{\circ} \mathrm{C}$ and $600^{\circ} \mathrm{C}$. All the samples showed wurtzite structure of $\mathrm{ZnO}$ with no secondary phase. The increase in doping concentration led to deterioration of crystalline quality, while improved crystallinity was observed at higher annealing temperature. The morphological study of these samples showed good grain-to-grain contact with less isolated pores. These samples were further characterized by impedance spectroscopy for analyzing dielectric properties. The values of the real part of dielectric constant and tangent loss showed decreasing trend with frequency. The appearance of semicircular arcs in the impedance complex plane plots indicates contribution of grains and grain boundaries and presence of different relaxation processes. $0.5 \% \mathrm{Al}$ and $\mathrm{Cu}$ codoped $\mathrm{ZnO}$ showed the best dielectric response with a high value of dielectric constant and low tangent loss.

\section{Introduction}

Energy is the crucial element for worldwide development. Oil price fluctuation, depletion of fossil fuel resources, and practical challenges in controlling environmental pollution have made renewable energy the most promising option. However, the high cost and unsteady nature of power production from these sources limit the use of renewable energy as a primary source. Therefore, the production of economical and efficient energy storage devices is crucial for using renewable energy for steady supply of power. Therefore, materials with high dielectric constant are becoming a continuous source of attraction due to their application in high energy storage applications. Extensive research has been carried out on ferroelectric-based materials and nonferroelectric like $\mathrm{CaCu}_{3} \mathrm{Ti}_{42} \mathrm{O}_{12}$ [1-5], to achieve high permittivity. However, frequency and temperature dependence of permittivity and high tangent loss have restricted their use in device miniaturization and high-frequency applications $[1,6,7]$. For the realization of high dielectric constant, one of the following phenomena must exist in the host material such as hopping charge transport, ferroelectricity, interface effects, metal insulator transition, or surface barrier layer capacitance (SBLC). In ceramic materials, colossal permittivity (CP) phenomena are attributed to internal barrier layer capacitance (IBLC) $[8,9]$, due to planar defects like twin and grain boundaries. Recently, a defect engineering approach was employed for the realization of high dielectric constant in oxide-based materials. The localization of carriers (electrons or holes) into substitutional defects and disorders like amorphous structure has been found responsible for CP. Moreover, hopping of localized defect state lowers tangent loss in these materials. Recently, frequency- and temperature-independent $\mathrm{CP}$ and low dielectric loss were achieved in In and $\mathrm{Nb}$ codoped $\mathrm{TiO}_{2}$ ceramic system. Donor $(\mathrm{Nb})$ and acceptor (In) substitution in $\mathrm{TiO}_{2}$ created local delocalized electron, consequently defect dipole-type clusters [4]. These electron-pinned defect dipoles were argued to be the reason for observed CP. Following this donor-acceptor substitution approach, there have been many reports in which CP with low dielectric loss has been achieved [9-11]. Efforts are still being made to fabricate CP materials with low dielectric losses, as no practical solution has yet been found for temperature and frequency stable 


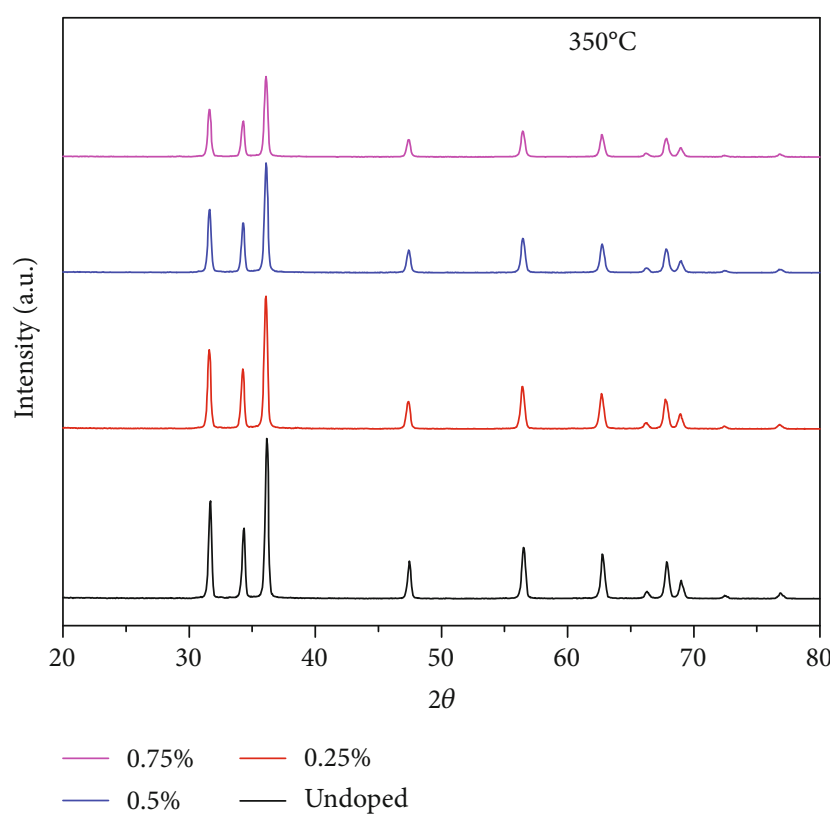

(a)

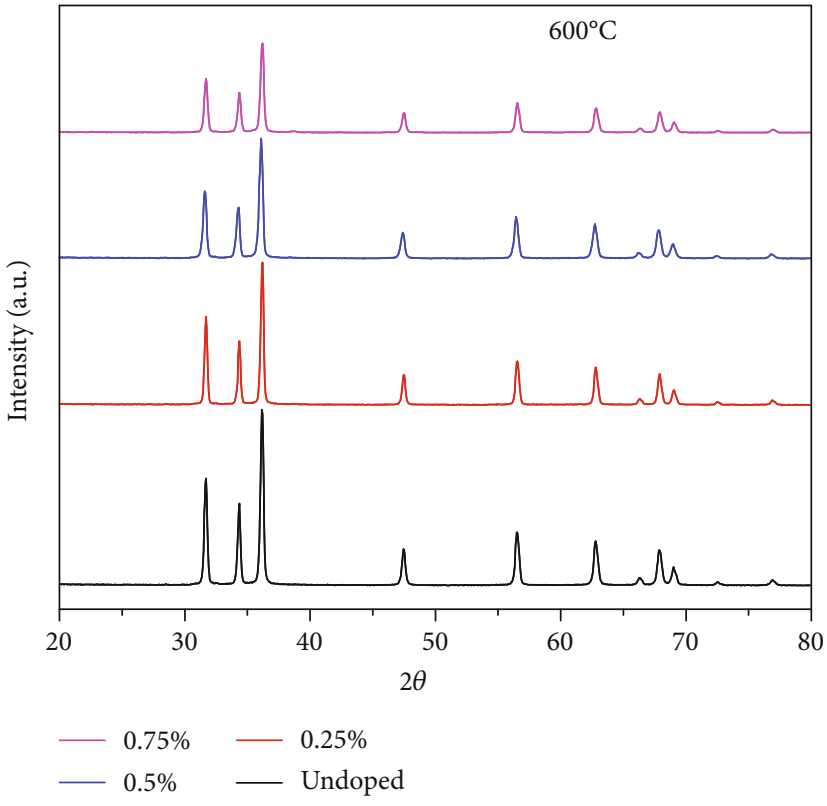

(b)

FIGURE 1: X-ray diffraction analysis of pristine and $\mathrm{Al}$ and $\mathrm{Cu}$ codoped $\mathrm{ZnO}$ with various doping concentrations annealed at (a) $350^{\circ} \mathrm{C}$ and (b) $600^{\circ} \mathrm{C}$.

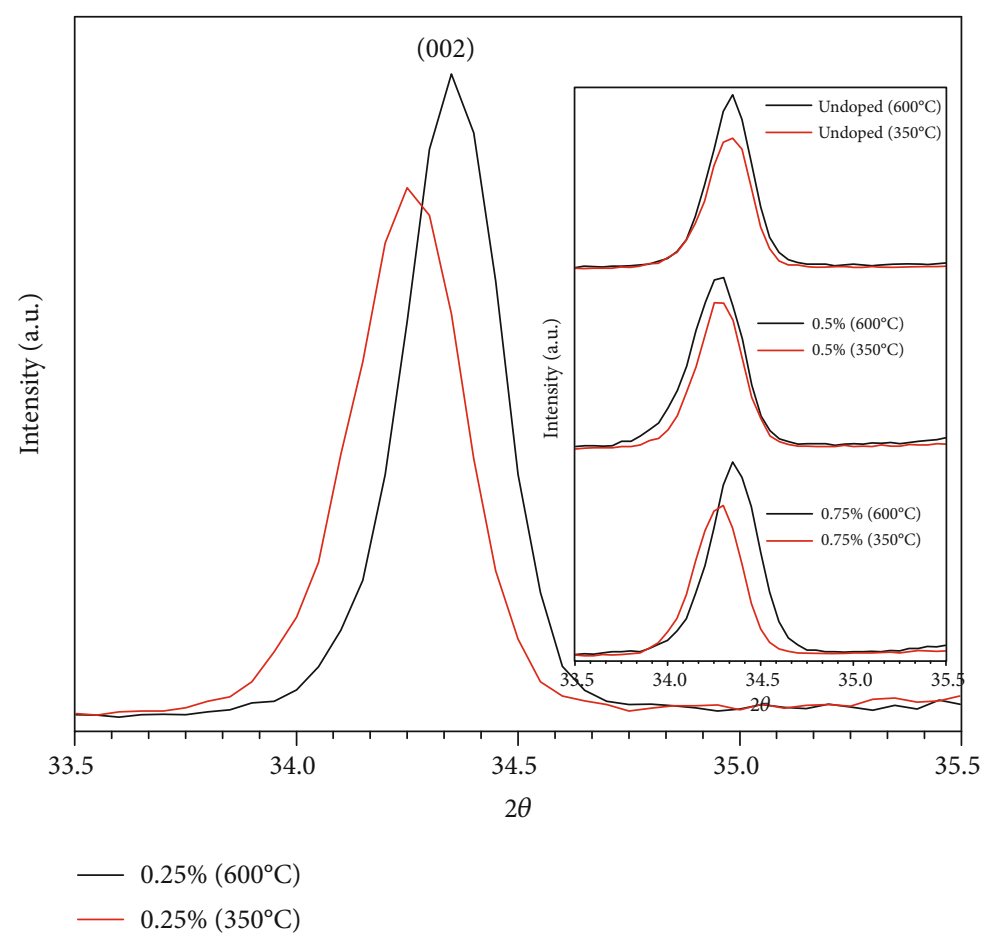

Figure 2: (002) diffraction peak of pristine and $\mathrm{Al}$ and $\mathrm{Cu}$ codoped $\mathrm{ZnO}\left(0.25 \%, 0.5 \%\right.$, and $0.75 \%$ annealed at $350^{\circ} \mathrm{C}$ and $600^{\circ} \mathrm{C}$.

permittivity and dielectric loss $[12,13]$. In this work, we have followed a similar approach by codoping $\mathrm{Al}$ (donor) and $\mathrm{Cu}$ (acceptor) in a wide-bandgap $\mathrm{ZnO}$ host. We synthesized $\mathrm{Al}$ and $\mathrm{Cu}$ codoped $\mathrm{ZnO}\left(\left(\mathrm{Al}_{0.5} \mathrm{Cu}_{0.5}\right)_{x} \mathrm{Zn}_{1-x} \mathrm{O}\right)$ samples with $x=0.25 \%, 0.50 \%$, and $0.75 \%$. X-ray diffraction (XRD) and scanning electron microscopy (SEM) were employed to characterize structural and morphological properties of the synthesized samples. The Williamson-Hall method was used to plot size-strain graphs. The bandgap energies of the synthesized samples were calculated using diffused reflectance spectroscopy (DRS). Impedance spectroscopy (IS) was carried out to study dielectric properties of these samples. We found that $0.5 \% \mathrm{Al}$ and $\mathrm{Cu}$ codoped $\mathrm{ZnO}$ showed relatively better results with high dielectric constant and low tangent loss. 


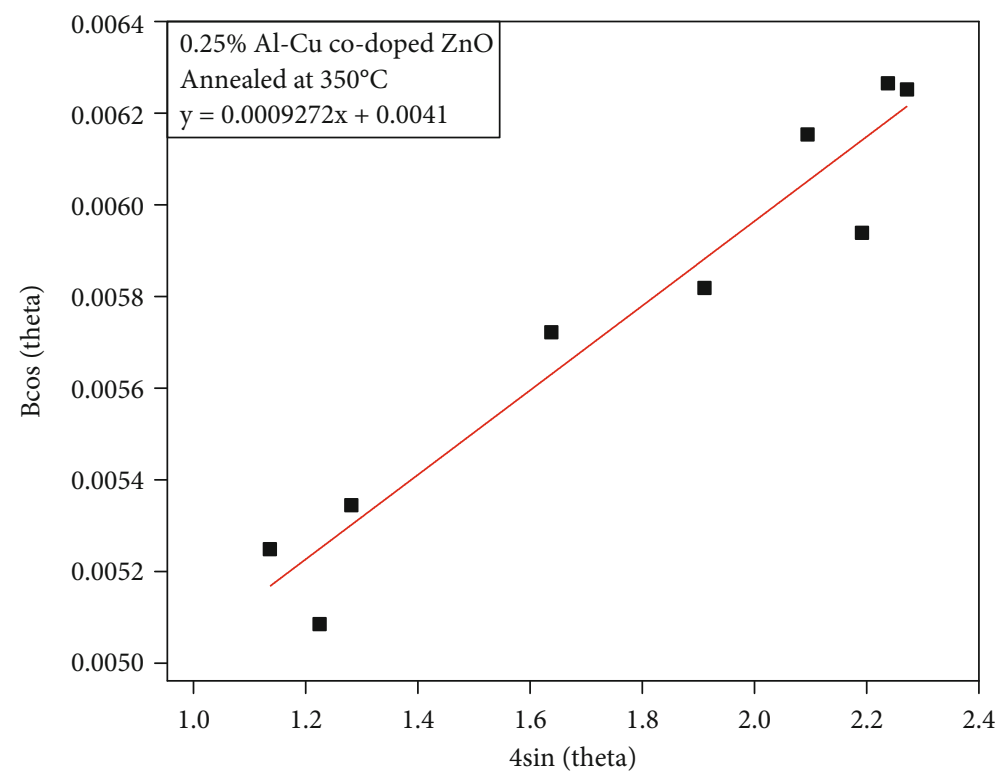

(a)

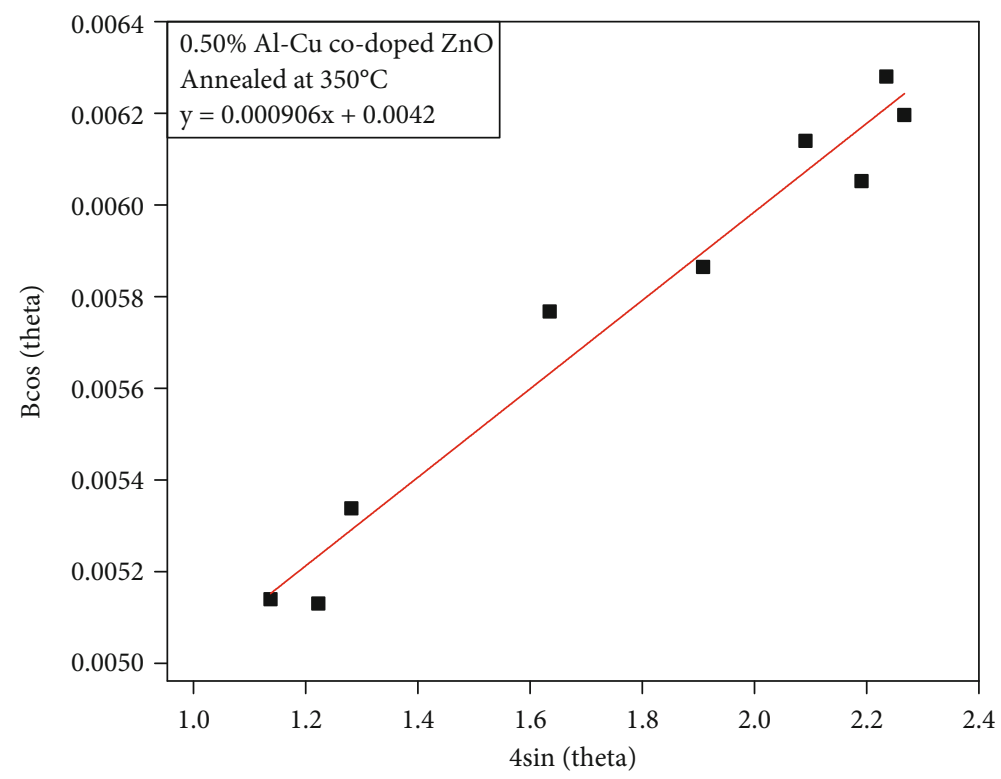

(b)

Figure 3: Continued. 


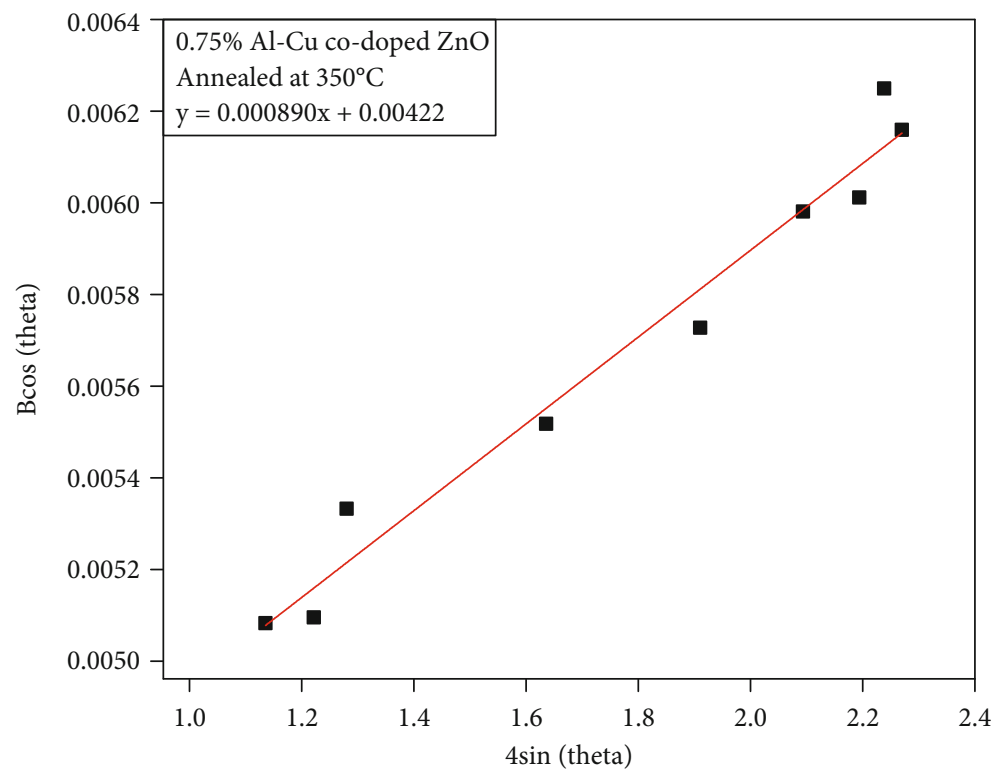

(c)

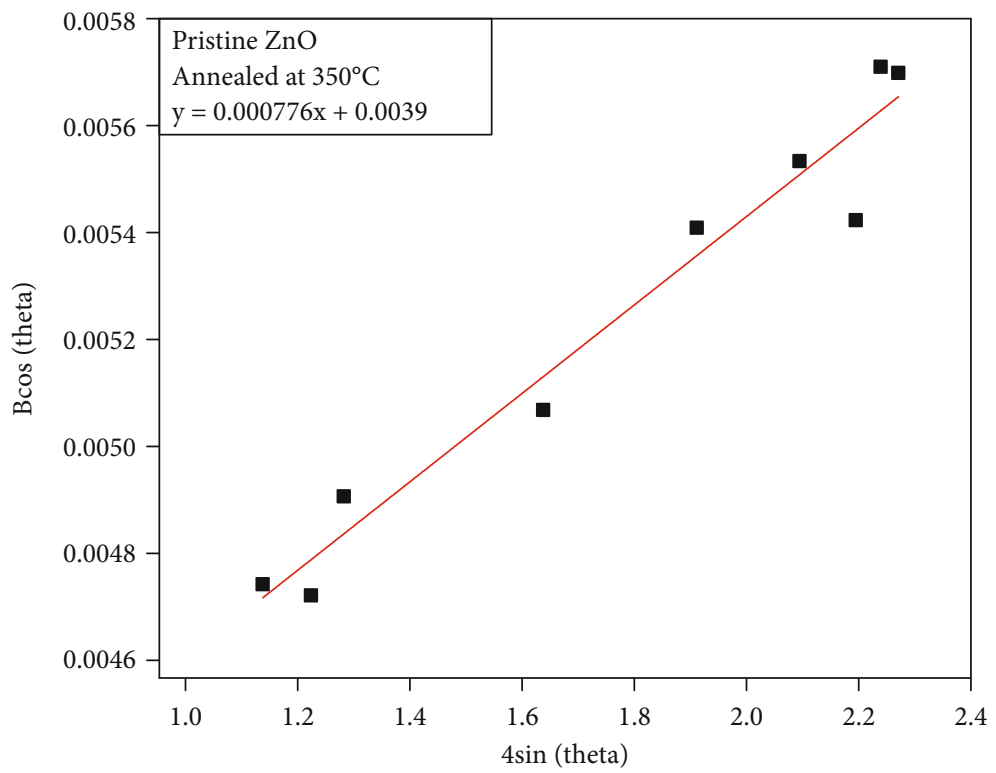

(d)

Figure 3: WH plots of (a) $0.25 \%$, (b) $0.5 \%$, (c) $0.75 \% \mathrm{Al}$ and $\mathrm{Cu}$ codoped $\mathrm{ZnO}$, and (d) pristine $\mathrm{ZnO}$ annealed at $350^{\circ} \mathrm{C}$.

\section{Experimental Setup}

Pristine and $\mathrm{Al}$ and $\mathrm{Cu}$ codoped $\mathrm{ZnO}$ with varied doping concentration were prepared using coprecipitation method. All the precursors were purchased from Sigma-Aldrich and used without any further purification. To synthesize undoped $\mathrm{ZnO}, 1 \mathrm{M}$ aqueous solution of zinc nitrate $\left(\mathrm{Zn}\left(\mathrm{NO}_{3}\right)_{2} \cdot 6 \mathrm{H}_{2} \mathrm{O}\right)$ was prepared in a beaker. $2 \mathrm{M}$ aq. $\mathrm{NaOH}$ solution was prepared separately in another beaker and added dropwise in the above solution at room temperature under constant stirring until $\mathrm{pH} 7$ was achieved [14]. The solution was kept stirring for 30 minutes after adding $\mathrm{NaOH}$ solution. The obtained precipitates were washed seven times with deionized water and then collected by centrifugation.
The following composition of $\mathrm{Al}_{0.5 x} \mathrm{Cu}_{0.5 x} \mathrm{Zn}_{1-x} \mathrm{O}$ with $x=$ $0.25,0.50$, and $0.75 \mathrm{~mol}$ was synthesized using the same method. Stoichiometric ratios of $\mathrm{Zn}\left(\mathrm{NO}_{3}\right)_{2} \cdot 6 \mathrm{H}_{2} \mathrm{O}$, $\mathrm{Al}\left(\mathrm{NO}_{3}\right)_{3} \cdot 9 \mathrm{H}_{2} \mathrm{O}$, and anhydrous $\mathrm{CuSO}_{4}$ were dissolved in deionized water to prepare homogenous solution. The obtained product was dried in an oven for 24 hours at $70^{\circ} \mathrm{C}$ and then annealed at $350^{\circ} \mathrm{C}$ and $600^{\circ} \mathrm{C}$ for 4 hours. The samples which were grown at higher $\mathrm{pH}$ showed development of secondary phase; therefore, all the samples were prepared in neutral phase.

An X-ray diffractometer (model: Bruker D8) at an incident wavelength of $1.5406 \AA$ was used to study structural properties. A scanning electron microscope (model: TESCAN VEGA-3) was employed for the morphological study 


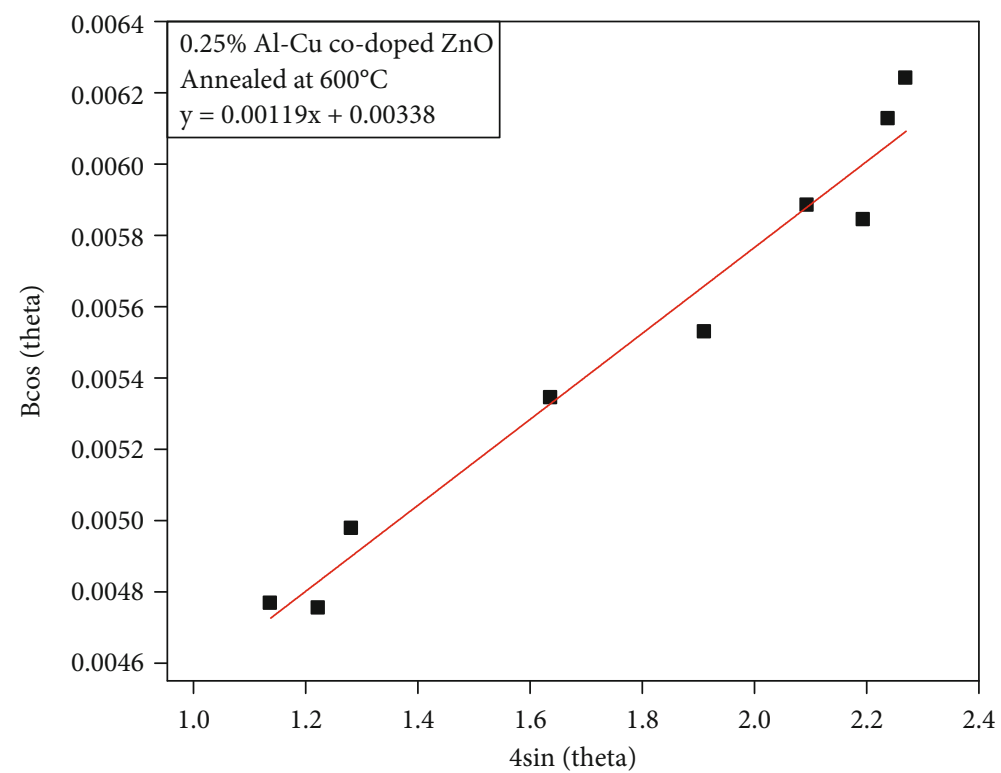

(a)

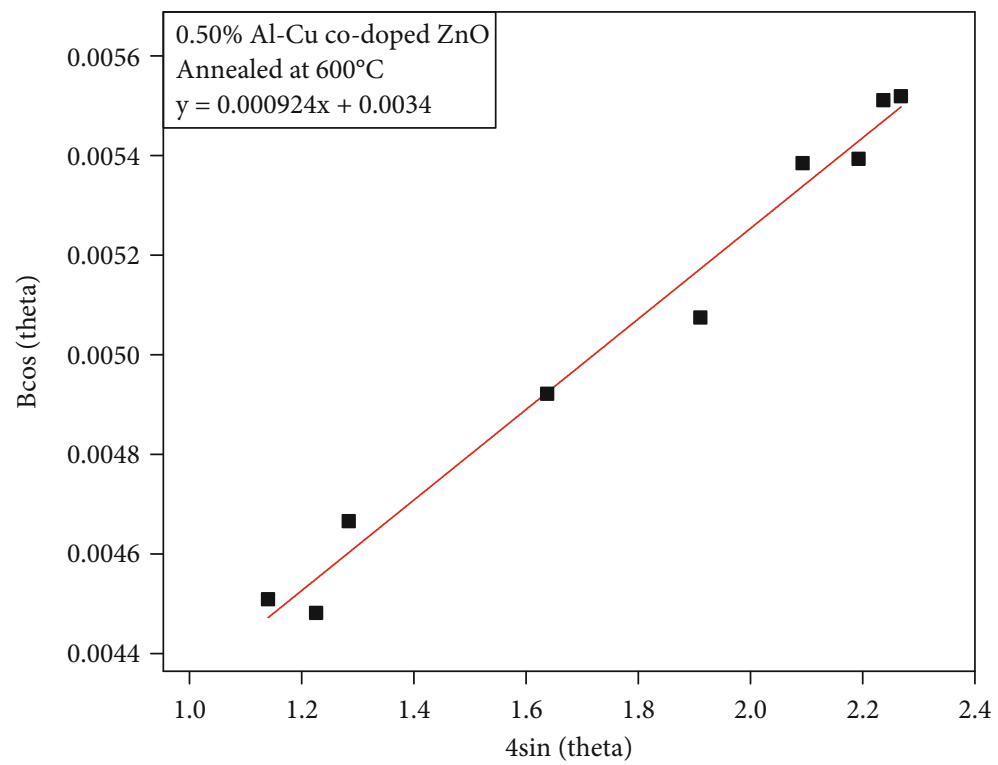

(b)

FIgURE 4: Continued. 


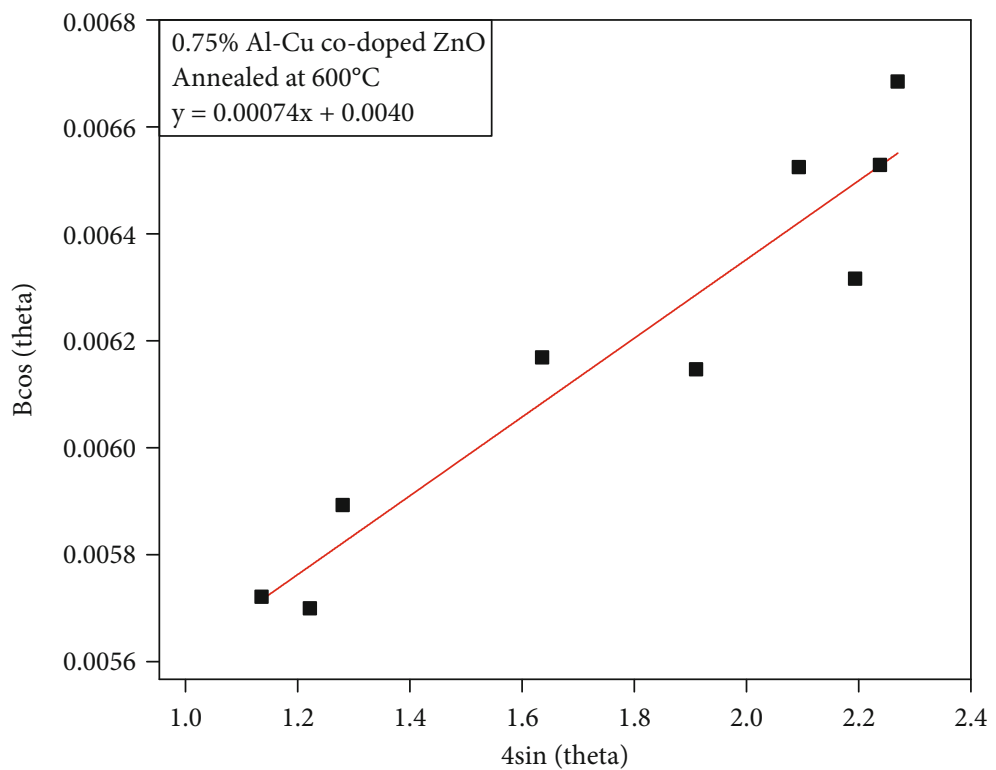

(c)

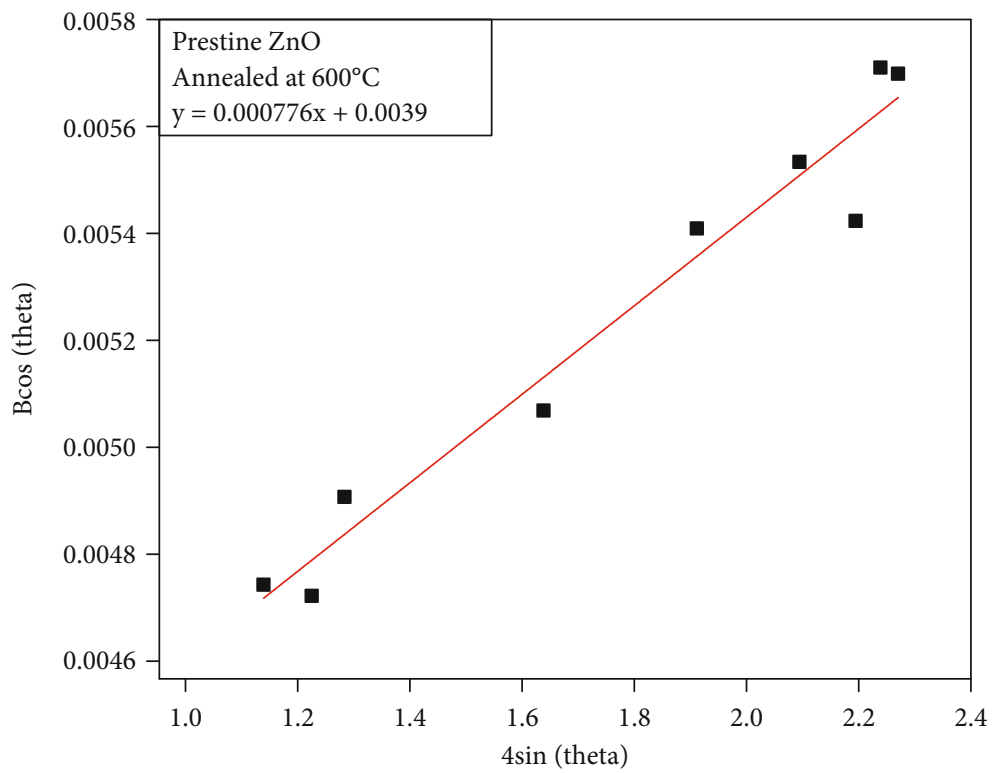

(d)

Figure 4: WH plots of (a) $0.25 \%$, (b) $0.5 \%$, (c) $0.75 \% \mathrm{Al}$ and $\mathrm{Cu}$ codoped $\mathrm{ZnO}$, and (d) pristine $\mathrm{ZnO}$ annealed at $600^{\circ} \mathrm{C}$.

TABLE 1: Crystallite size $(D)$, strain $(\varepsilon)$, dislocation density $(\delta)$, and lattice parameters $(a, c)$ of pristine and $\mathrm{Al}$ and $\mathrm{Cu}$ codoped $\mathrm{ZnO}(0.25 \%$, $0.5 \%$, and $0.75 \%$ ) annealed at $350^{\circ} \mathrm{C}$ and $600^{\circ} \mathrm{C}$.

\begin{tabular}{|c|c|c|c|c|c|c|c|c|c|c|}
\hline \multirow{2}{*}{ Sample name } & \multicolumn{5}{|c|}{ Annealed at $350^{\circ} \mathrm{C}$} & \multicolumn{5}{|c|}{ Annealed at $600^{\circ} \mathrm{C}$} \\
\hline & $D(\mathrm{~nm})$ & Strain $(\varepsilon)$ & $\delta\left(\mathrm{nm}^{-2}\right)$ & $a(\AA)$ & $c(\AA)$ & $D(\mathrm{~nm})$ & Strain $(\varepsilon)$ & $\delta\left(\mathrm{nm}^{-2}\right)$ & $a(\AA)$ & $c(\AA)$ \\
\hline Pristine $\mathrm{ZnO}$ & 35.53 & $1.76 E-03$ & $7.92 E-04$ & 3.34 & 5.46 & 45.53 & $2.17 E-03$ & $4.82 E-04$ & 3.31 & 5.43 \\
\hline $0.25 \%$ codoped $\mathrm{ZnO}$ & 33.80 & $0.90 E-03$ & $8.75 E-04$ & 3.25 & 5.31 & 41.06 & $1.19 E-03$ & $5.93 E-04$ & 3.23 & 5.29 \\
\hline $0.50 \%$ codoped $\mathrm{ZnO}$ & 33.00 & $0.90 E-03$ & $9.18 E-04$ & 3.19 & 5.21 & 40.76 & $0.92 E-03$ & $6.01 E-04$ & 3.19 & 5.21 \\
\hline $0.75 \%$ codoped $\mathrm{ZnO}$ & 32.84 & $0.89 E-03$ & $9.27 E-04$ & 3.16 & 5.11 & 34.65 & $0.74 E-03$ & $8.32 E-04$ & 3.12 & 5.07 \\
\hline
\end{tabular}

of the synthesized samples; compositional analysis was carried out using the attached EDX assembly. Bandgap analysis of the samples was carried out by diffused reflectance spectroscopy (model: lambda 365). Room temperature imped- ance spectroscopy was performed in frequency range 1$10^{7} \mathrm{~Hz}$ using an Alpha-N Analyzer (Novocontrol, Germany). Samples were fixed into a sample holder by binding copper wires on both sides using silver paint. AC signal of 
$0.5 \mathrm{~V}$ was applied on all the samples. WINDETA software was used for interfacing experimental setup of the analyzer with the computer for data acquisition.

\section{Results and Analysis}

$\mathrm{X}$-ray diffraction patterns of pristine and $\mathrm{Al}$ and $\mathrm{Cu}$ codoped samples at a doping concentration of $0.25 \%, 0.5 \%$, and $0.75 \%$ annealed at $350^{\circ} \mathrm{C}$ and $600^{\circ} \mathrm{C}$ are shown in Figure 1. All the samples show a hexagonal wurtzite structure of $\mathrm{ZnO}$. The peaks could be indexed as (100), (002), (101), (102), (110), (103), (200), (112), (201), (204), and (202) in accordance with JCPDF-01-079-0208. No unidentified diffraction peak related to any secondary phase was observed in all the diffraction patterns. All the samples showed a well-defined peak profile with reasonable intensity that indicates good crystalline quality. A decrease in the peak intensity was observed with increase in doping concentration at both annealing temperatures which shows deterioration of crystallinity with increase in doping concentration $[15,16]$.

Figure 2 shows (002) peak profile of $0.25 \% \mathrm{Al}$ and $\mathrm{Cu}$ codoped $\mathrm{ZnO}$ sample annealed at $350^{\circ} \mathrm{C}$ and $600^{\circ} \mathrm{C}$. The graph shows an increase in the peak intensity and decrease in full width at half maximum (FWHM) with increase in annealing temperature. Furthermore, a shift in the peak position of (002) peak was also observed with annealing temperature. Similar effects were also observed in other samples, and data is shown in the inset of Figure 2. The increase in peak intensity along with decreased FWHM indicates improvement of crystallinity upon annealing at higher temperature [17]. This enhancement of crystalline quality is due to grain growth at high temperature. The shift of (002) diffraction peak towards higher angle with annealing (at higher temperature) is linked with the change in microstrain [18]. This phenomenon was also reported in pristine and other doped nanoparticles of $\mathrm{ZnO}$ [17]. This change in microstrain might be associated with decreased lattice parameters due to formation of oxygen vacancy at higher annealing temperature [17] because of doping. Felemban et al. [19] also reported that isolated oxygen vacancy introduces contraction of both lattice parameters. Furthermore, $\mathrm{ZnO}$ nanoparticles have different defects that reportedly happen to disappear when the sample is annealed at high temperature resulting to the shrinkage of lattice parameters [20]. Therefore, it might be inferred that an increase in annealing temperature leads to varied defect chemistry (in doped samples) that reduces the lattice strain and corresponding lattice parameter.

The Williamson-Hall (WH) method was used to analyze crystallite size $(D)$ and microstrain of pristine $\mathrm{ZnO}$ and $\mathrm{Al}$ and $\mathrm{Cu}$ codoped $\mathrm{ZnO}$ at various doping concentrations and annealing temperatures (Figures 3(a)-3(d) and Figures 4(a)-4(d)). The crystallite size $(D)$, microstrain, dislocation density, and lattice parameters of these samples are shown in Table 1 . The $D$ value of the samples decreases with increase in doping concentration at each annealing temperature; the maximum $D$ value was obtained for pristine $\mathrm{ZnO}$ [21]. An increase in the $D$ value was observed with annealing temperature in pristine and codoped samples at a fixed dop-

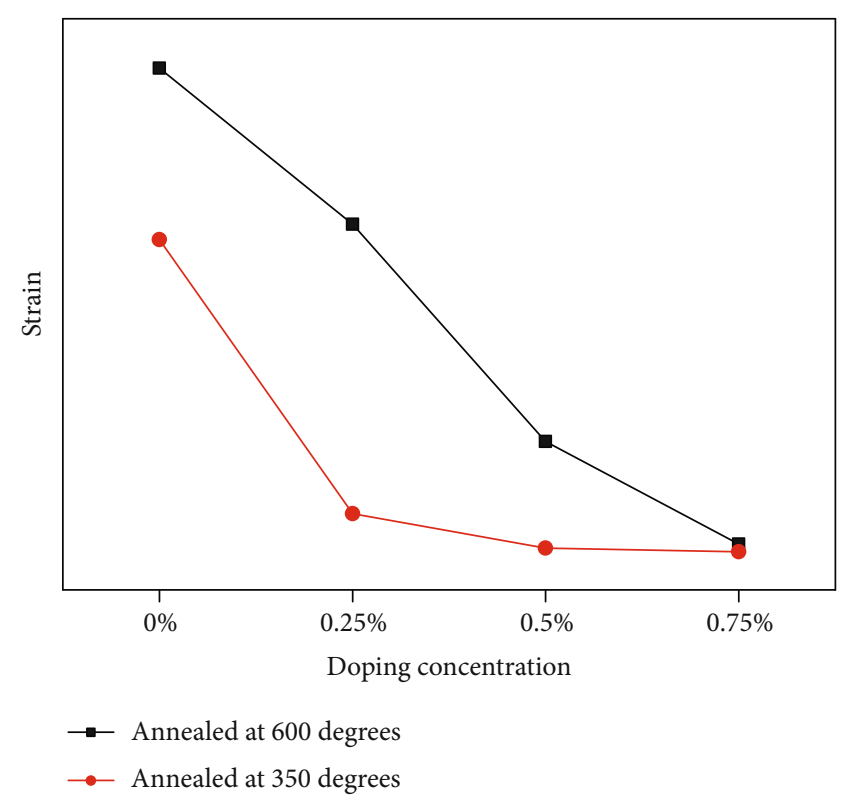

Figure 5: Trend of microstrain as a function of doping concentration of $\mathrm{Al}$ and $\mathrm{Cu}$ codoped $\mathrm{ZnO}$ annealed at $350^{\circ} \mathrm{C}$ and $600^{\circ} \mathrm{C}$.

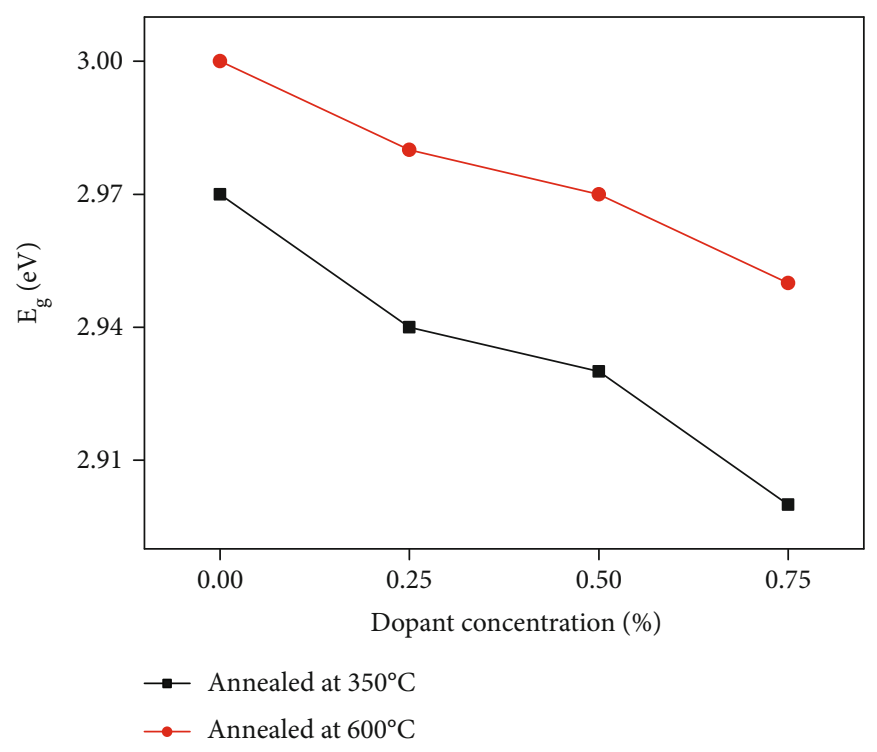

FIgURe 6: Bandgap energy of $\mathrm{Al}$ and $\mathrm{Cu}$ codoped $\mathrm{ZnO}(0 \%, 0.25 \%$, $0.5 \%$, and $0.75 \%$ ) annealed at $350^{\circ} \mathrm{C}$ and $600^{\circ} \mathrm{C}$.

ing concentration. The dislocation density was found to increase with doping concentration at a fixed annealing temperature and decrease with increase in annealing temperature at a fixed doping concentration. Furthermore, shrinkage of lattice parameters was observed with doping concentration at a fixed annealing temperature in these samples which indicates reduction of cell volume [22]. This decrease of $D$-value, increase of dislocation density, and shrinkage of lattice parameters with doping concentration indicate deterioration of crystalline quality due to lattice mismatch [23], whereas increase of $D$-value and decrease of dislocation density at fixed doping concentration with 


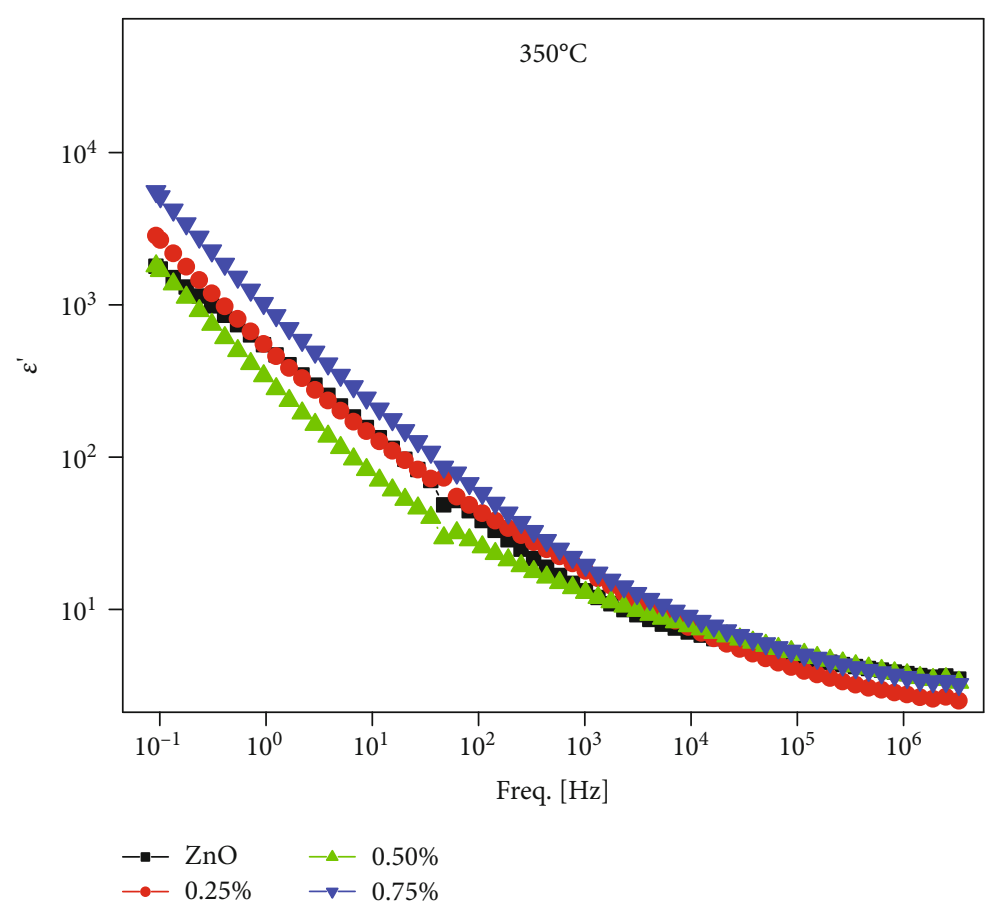

(a)

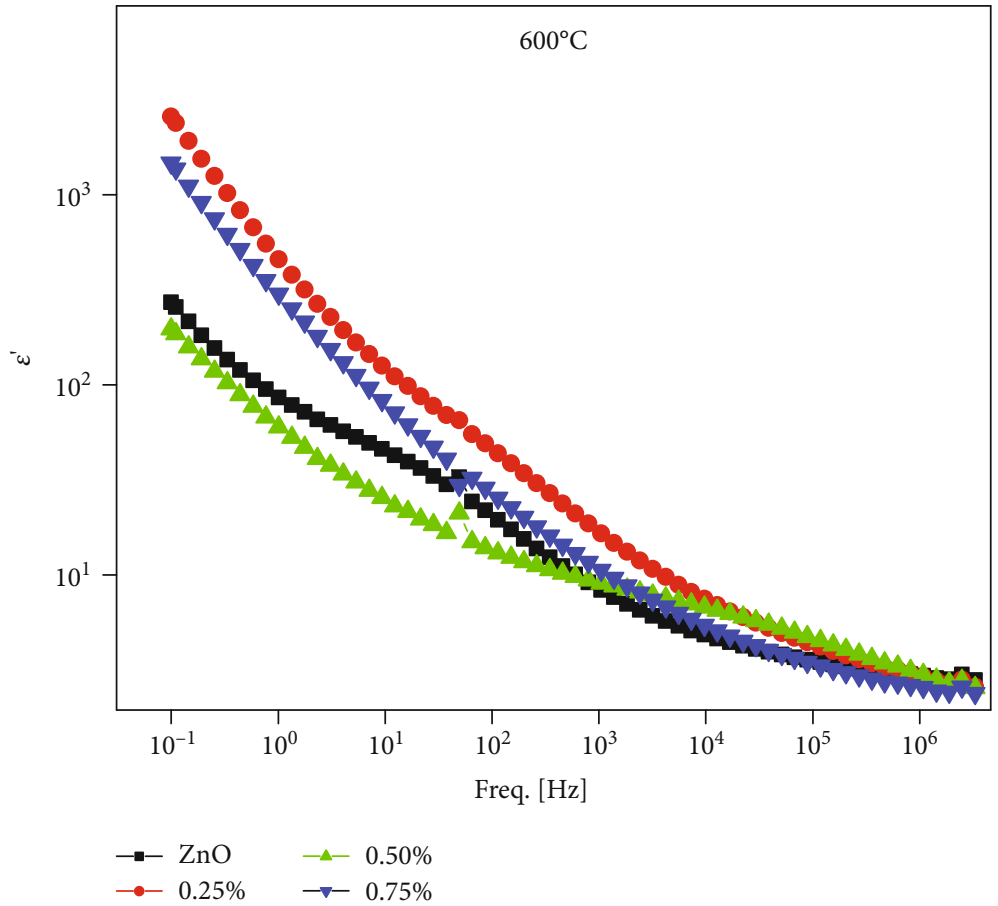

(b)

Figure 7: Dielectric constant of $\mathrm{Al}$ and $\mathrm{Cu}$ codoped $\mathrm{ZnO}(0 \%, 0.25 \%, 0.5 \%$, and $0.75 \%)$ annealed at (a) $350^{\circ} \mathrm{C}$ and (b) $600^{\circ} \mathrm{C}$.

annealing temperature specify improvement of the crystalline quality [24]. These results are in accordance with the intensity data explained above.

The data of microstrain as a function of doping concentration and annealing temperature is also presented in Figure 5. An increase in the microstrain was observed when the samples were annealed at $600^{\circ} \mathrm{C}$ as compared to when annealed at $350^{\circ} \mathrm{C}$. Both the series of samples have lesser microstrain as compared to pristine $\mathrm{ZnO}(0 \%)$. A decrease in the value of microstrain was observed with the doping concentration at $600^{\circ} \mathrm{C}$; however, the value of microstrain does not show appreciable dependence on doping concentration at $350^{\circ} \mathrm{C}$. This decrease in the microstrain might be linked with varied defect chemistry of the samples with 


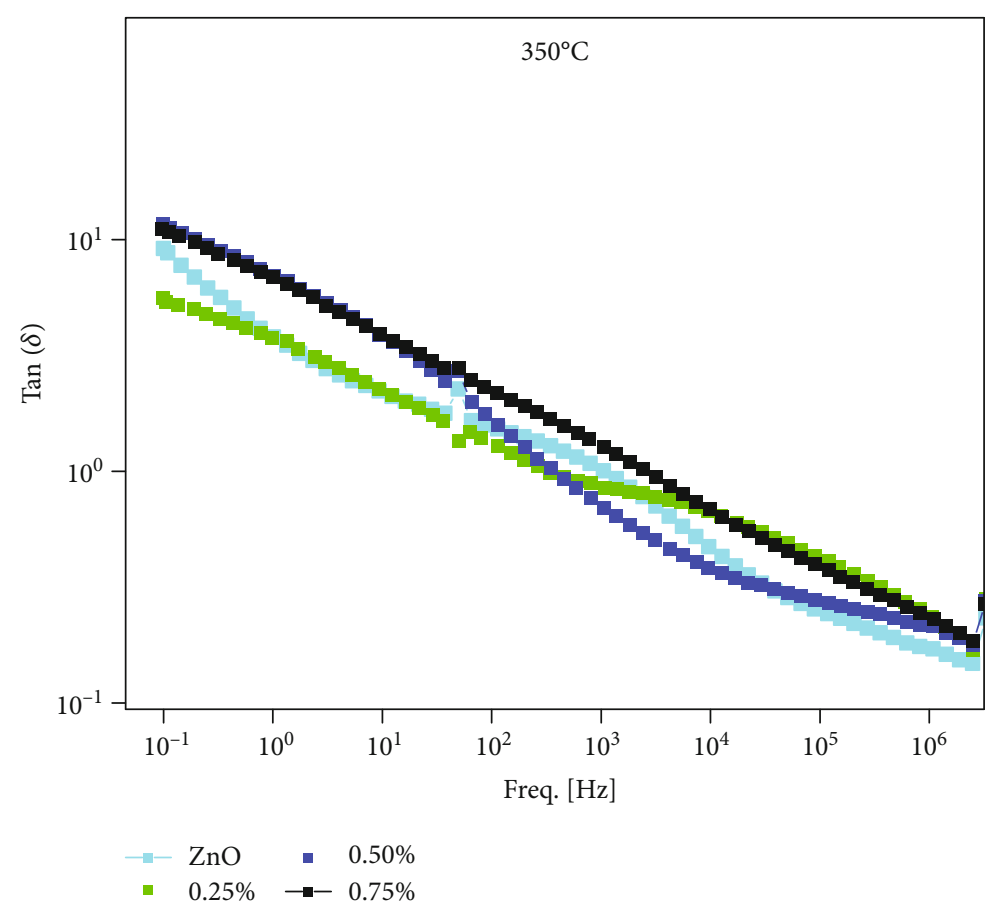

(a)

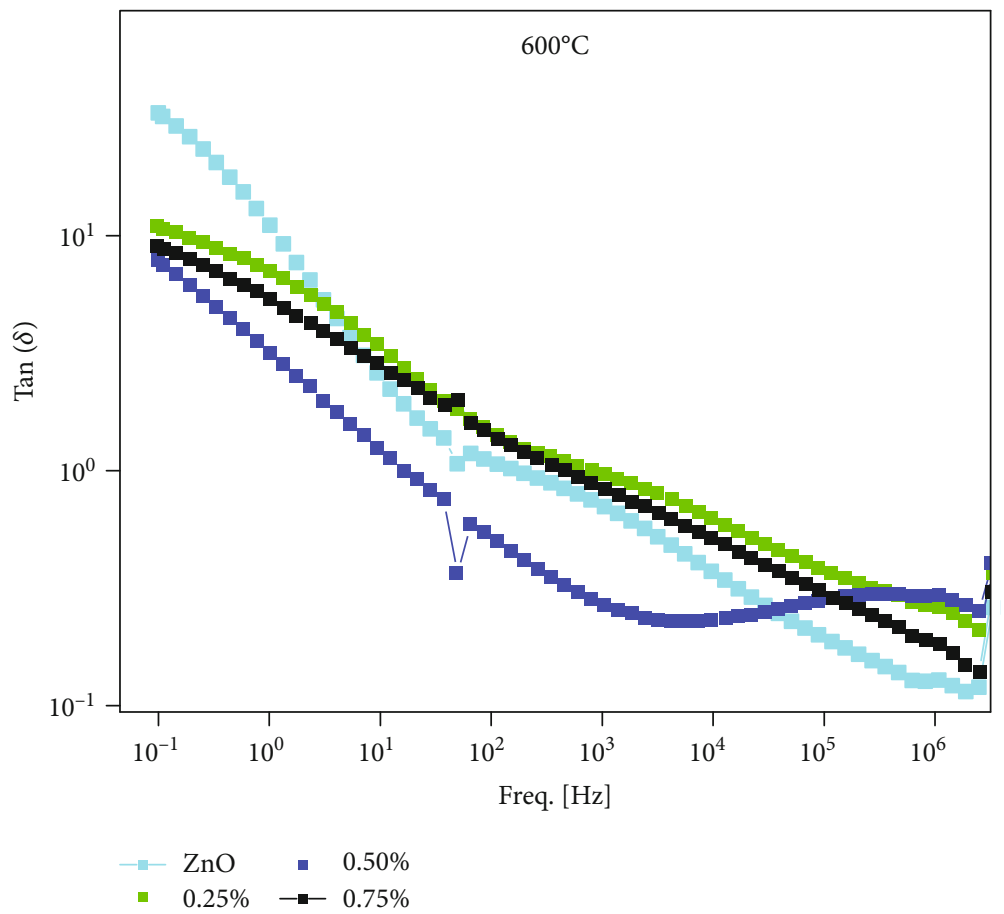

(b)

Figure 8: Tangent loss as a function of frequency for $\mathrm{Al}$ and $\mathrm{Cu}$ codoped $\mathrm{ZnO}(0 \%, 0.25 \%, 0.5 \%$, and $0.75 \%)$ annealed at (a) $350^{\circ} \mathrm{C}$ and (b) $600^{\circ} \mathrm{C}$.

doping at different temperatures [24]. Furthermore, all the samples showed positive values of microstrain which is indicative of intrinsic tensile strain [25].

The bandgap energy $\left(E_{\mathrm{g}}\right)$ of all samples was calculated using diffused reflectance spectroscopy. Figure 6 shows the bandgap of $\mathrm{Al}$ and $\mathrm{Cu}$ codoped $\mathrm{ZnO}$ at different annealing temperatures and doping concentrations. There is a visible decrease in the bandgap due to the increase in doping concentration at both annealing temperatures, while an increase in the bandgap was observed at a fixed doping concentration with increasing annealing temperature. The doping of an element in a semiconductor host generates localized state within the bandgap of the host. The donor impurities often create these localized states near conduction band edge and 


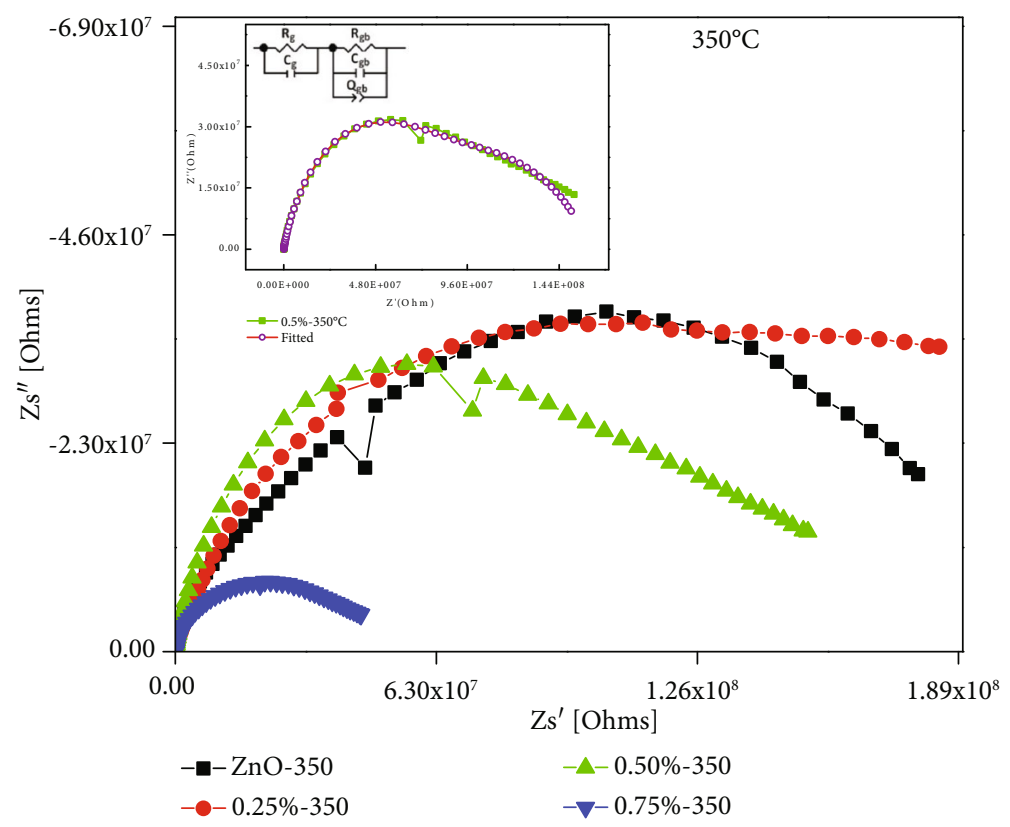

(a)

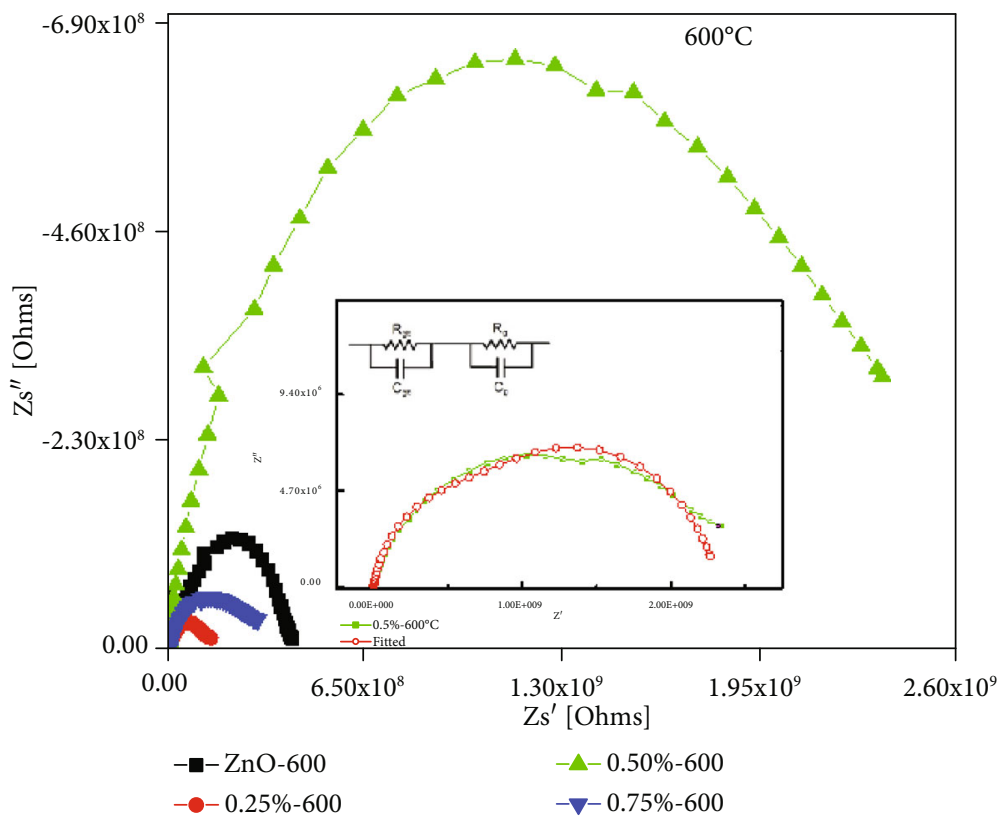

(b)

Figure 9: Nyquist plots of $\mathrm{Al}$ and $\mathrm{Cu}$ codoped $\mathrm{ZnO}(0 \%, 0.25 \%, 0.5 \%$, and $0.75 \%)$ annealed at (a) $350^{\circ} \mathrm{C}$ and (b) $600^{\circ} \mathrm{C}$.

acceptor impurity near valence band edge. The increase in doping concentration of donor and acceptor impurity raises the number of these localized states which results in continuum impurity band formation above valence band edge and below conduction band edge [26]. The bandgap narrowing in these samples with doping might be due to creation of these localized states in the bandgap near the conduction band and valence band edge, respectively [24]. Hence, bandgap decreases with an increase in doping concentration. The increase in bandgap with annealing has been linked with the increase of crystallite size upon annealing at higher temper- atures [27]. The energy levels in semiconductors are dependent on the degree of structural order-disorder in the lattice [28]. Therefore, the increase of structural organization in nanoceramic leads to a reduction of the intermediary energy levels which consequently increases $E_{\mathrm{g}}$.

Impedance spectroscopy was performed on these samples. Figures 7(a) and 7(b) show the real part of dielectric constant $\left(\varepsilon^{\prime}\right)$ as a function of frequency at annealing temperature of $350^{\circ} \mathrm{C}$ and $600^{\circ} \mathrm{C}$, respectively. All the doped and pristine $\mathrm{ZnO}$ samples at both annealing temperatures showed relatively high value of $\varepsilon^{\prime}$ at low frequencies which 


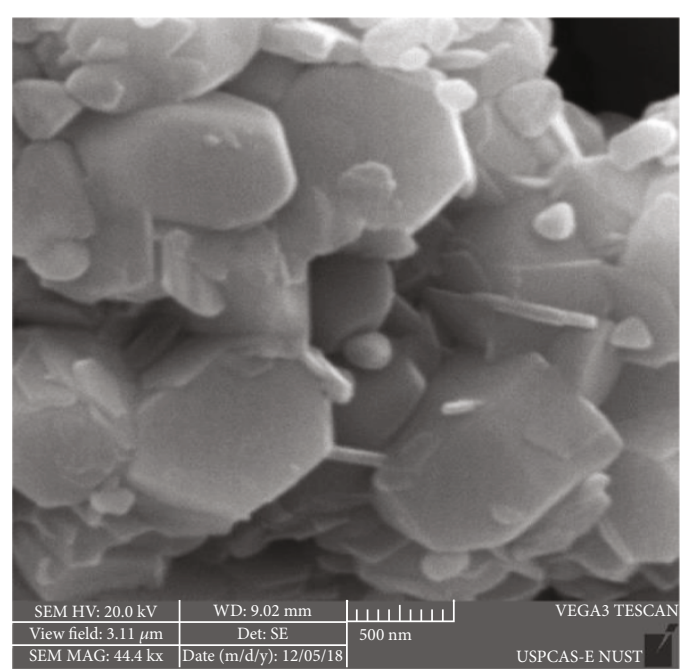

(a)

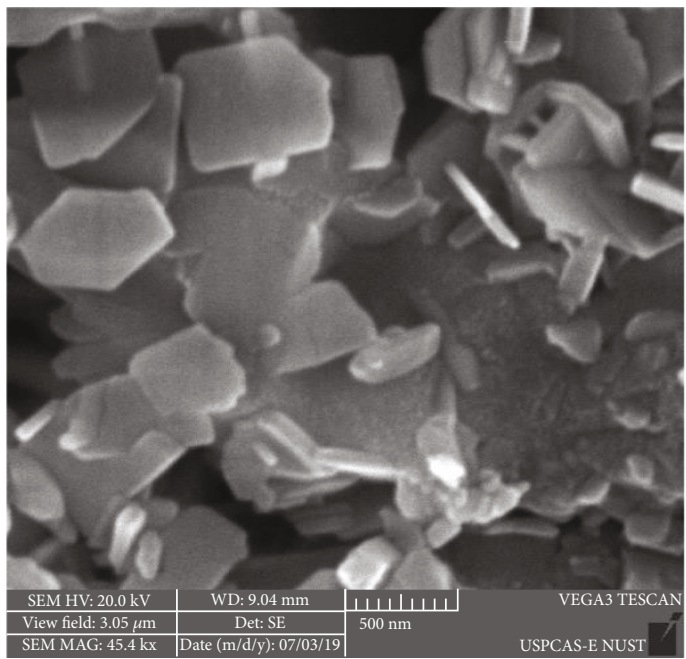

(c)

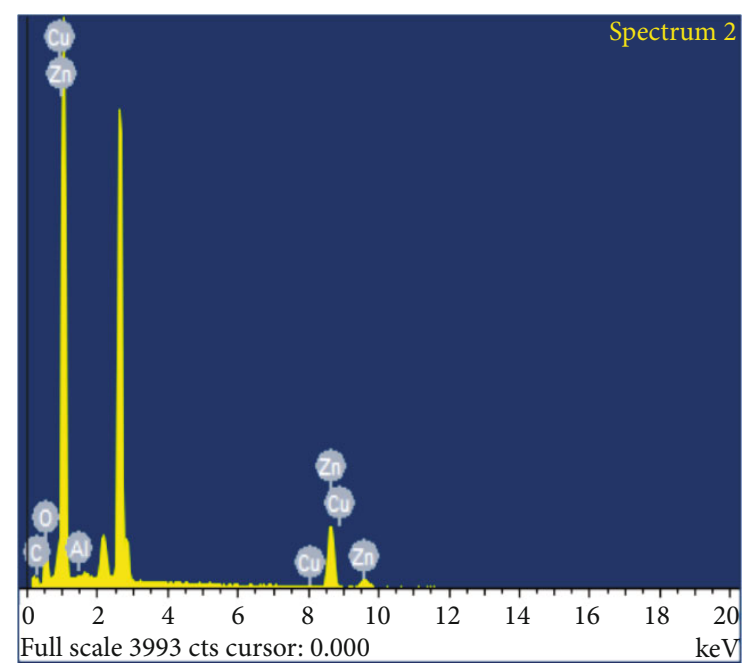

(b)

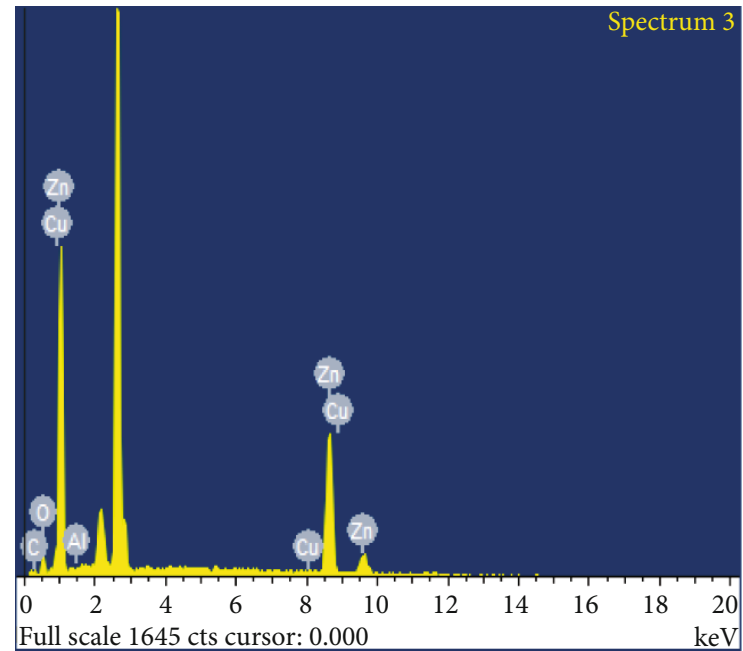

(d)

Figure 10: $(\mathrm{a}, \mathrm{c})$ Show SEM micrographs of $0.5 \% \mathrm{Al}$ and $\mathrm{Cu}$ codoped $\mathrm{ZnO}$ annealed at $600^{\circ} \mathrm{C}$ and $350^{\circ} \mathrm{C}$, respectively. EDX spectrum of $0.5 \% \mathrm{Al}$ and $\mathrm{Cu}$ codoped $\mathrm{ZnO}$ annealed at $600^{\circ} \mathrm{C}$ and $350^{\circ} \mathrm{C}$ is shown in (b) and (d), respectively.

decreases with increase in frequency. The decrease in $\varepsilon^{\prime}$ with respect to frequency can be attributed to the lagging of carriers as they find it difficult to reach the grain boundaries [29]. This mechanism is common in metal oxides and referred as frequency dispersion. The Maxwell-Wagner interfacial model is used to explain the dielectric behavior of transparent metal oxides as they are composed of conducting grains differentiated by less-conducting grain boundaries. When a field is applied at lower frequencies, the charge carriers could easily pass through the grains, but at grain boundaries, they accumulate. This process is defined as high interfacial polarization which leads to high dielectric constant [30]. At high frequencies, these charge carriers fail to respond to applied frequency which results in the diminishment of interfacial polarization. The only types of polarization that sustain high applied AC frequency are electronic and ionic polarization. Therefore, a reduction in the value of $\varepsilon^{\prime}$ with frequency was observed.
Tangent loss of pristine and the codoped $\mathrm{ZnO}$ at both annealing temperatures was also studied. The data is shown in Figures 8(a) and 8(b). In all the samples, tangent loss was found to be decreasing as the frequency was increased. This decrease in tangent loss with frequency is attributed to the release of space charges trapped at grain boundaries [30]. The trend of tangent loss with frequency can be explained by Koop's theory. $0.5 \% \mathrm{Al}$ and $\mathrm{Cu}$ codoped $\mathrm{ZnO}$ which was annealed at $600^{\circ} \mathrm{C}$ showed the most balanced results with low dielectric loss and high dielectric constant. The value of tangent loss at $100 \mathrm{~Hz}$ was found to be 0.53 which further reduced and became constant in the frequency range above $10^{3} \mathrm{~Hz}$.

Figures 9(a) and 9(b) show complex impedance plane plots of pristine and $\mathrm{Al}$ and $\mathrm{Cu}$ codoped $\mathrm{ZnO}$ samples at an annealing temperature of $350^{\circ} \mathrm{C}$ and $600^{\circ} \mathrm{C}$. The inset in each figure shows the best fitted simulated results of the equivalent circuit along with experimental data. Straight 
lines along real and imaginary axis show pure resistive and pure capacitive behavior, respectively [31]. A parallel combination of resistance $(R)$ and capacitance $(C)$ makes a semicircle. Therefore, two $R C$ parallel circuits connected in series describe contribution of two semicircles: one in the lower and other in the higher frequency range, in the Nyquist plot (Figures 9(a) and 9(b)) of these samples indicating two types of relaxation processes. In metal oxide, the grain boundaries are highly resistive because of the nonstoichiometric distribution of oxygen, spin charge reflection, and dangling bonds. These highly resistive layers have large capacitance due to their very thin size [32]. Therefore, high resistance and high capacitance of grain boundaries lead to a higher time constant [18]. Thus, the semicircle at lowfrequency range corresponds to grain boundaries and that at higher frequency shows contribution due to grains in each sample. The electrode contribution was not observed in any of these samples.

To investigate morphology, grain growth, and porosity in $0.5 \% \mathrm{Al}$ and $\mathrm{Cu}$ codoped $\mathrm{ZnO}$ samples annealed at $350^{\circ} \mathrm{C}$ and $600^{\circ} \mathrm{C}$, detailed high-resolution scanning electron microscopy (SEM) was performed as shown in Figures 10(a) and 10(c). SEM surface micrographs confirm that substitution did not cause any prominent change in the microstructure of the sample. Annealing at high temperature leads to the formation of large structures at the cost of diffusion of tiny particles into surrounding particles. The pores between particles are difficult to escape during annealing process. Beyond the critical porosity values, pores start to be connected to one another thereby forming continuous paths and turn into open pores. The increased number of open pores is associated with decreased amount of grain-tograin connection. The SEM micrograph demonstrates very good grain-to-grain contact with a minimum number of isolated pores [33]. This indicates the presence of isolated closed pores dispersed in ceramic bulk. The intimate contact, in the SEM images, between $\mathrm{ZnO}$ grains should produce promising electron transportation properties in the sample.

To find out the possible existence of metal cluster and foreign elements at grain and grain boundaries, we have also done energy-dispersive X-ray (EDX) spectroscopy analysis at different areas of grain and grain boundaries of all the annealed $\mathrm{ZnO}$ samples (Figures 10(b) and 10(d)). The EDX analysis on the sintered samples reveals only zinc and oxygen atoms belonging to the native $\mathrm{ZnO}$ matrix. The dust-like particles on the surface of each micrograph also belong to the $\mathrm{ZnO}$ and have nothing to do with impurity atoms. Within the detection limit of EDX, we could not observe any foreign atom or metal clustering at grains and grain borders of all pristine samples of $\mathrm{ZnO}$ annealed at different temperatures.

\section{Conclusion}

In summary, pristine and $\mathrm{Cu}$ and $\mathrm{Al}$ codoped $\mathrm{ZnO}$ nanoparticles were synthesized using the coprecipitation method to investigate the effect of doping and annealing temperature on the structural, morphological, and dielectric properties.
XRD results showed that all the samples have a wurtzite structure with no secondary phase. The increase in doping concentration led to deterioration in crystalline quality, while annealing at high temperature improved crystallinity. The microstrain in the lattice decreased with doping due to varied defect chemistry. Bandgap narrowing was noticed in these samples upon doping due to the generation of localized defect level inside the bandgap, whereas the samples annealed at higher temperature showed bandgap widening due to reduction in intermediate level because of enhanced structural organization. Dielectric characterization of the samples disclosed interfacial polarization at lower frequencies which diminshes at higher frequencies. The appearance of semicircular arcs in the impedance complex plane plots confirmed the contribution of grains and grain boundaries and presence of different relaxation processes in these samples. Adding both donor and acceptor ion simultaneously in $\mathrm{ZnO}$ resulted in the decreased dielectric loss of sample materials. However, $0.5 \% \mathrm{Al}, \mathrm{Cu}$ codoped $\mathrm{ZnO}$ annealed at $600^{\circ} \mathrm{C}$ showed the most balanced results with low dielectric loss and high dielectric constant. Furthermore, SEM results confirmed good grain-to-grain contact with a minimum number of isolated pores. This study has provided a unique way to tailor dielectric properties of $\mathrm{ZnO}$ which has remarkable application in next-generation supercapacitors for energy storage applications.

\section{Data Availability}

The corresponding author should be contacted to get data. The contact details of the corresponding author are as follows: Dr. Fahad Azad, School of Natural Sciences, National University of Sciences and Technology, Islamabad, Pakistan (fahad.azad@sns.nust.edu.pk).

\section{Additional Points}

(i) Impedance analysis of donor $(\mathrm{Al}) /$ acceptor $(\mathrm{Cu})$ codoped $\mathrm{ZnO}$ nanoparticles, (ii) effect of thermal annealing on the structural and dielectric properties $\left(350-600^{\circ} \mathrm{C}\right.$ ), and (iii) optimized concentration of donor and acceptor doping found useful for superior dielectric properties.

\section{Conflicts of Interest}

The authors declare that they have no conflicts of interest.

\section{Acknowledgments}

We would like to thank Dr. Muhammad Younas (late) who died of COVID-19. His help in the data collection and result interpretation is highly appreciated.

\section{References}

[1] M. Buscaglia, M. Viviani, V. Vuscaglia et al., "High dielectric constant and frozen macroscopic polarization in dense nanocrystallineBaTiO3ceramics," Physical Review B, vol. 73, no. 6, article 064114, 2006. 
[2] J. Wu, C.-W. Nan, Y. Lin, and Y. Deng, "Giant Dielectric Permittivity Observed in Li and Ti Doped NiO," Physical Review Letters, vol. 89, no. 21, article 217601, 2002.

[3] M. A. Subramanian, D. Li, N. Duan, B. A. Reisner, and A. W. Sleight, "High Dielectric Constant in ACu3Ti4O12 and ACu3Ti3FeO12 Phases," Journal of Solid State Chemistry, vol. 151, no. 2, pp. 323-325, 2000.

[4] W. Hu, Y. Liu, R. L. Withers et al., "Electron-pinned defectdipoles for high-performance colossal permittivity materials," Nature Materials, vol. 12, no. 9, pp. 821-826, 2013.

[5] S. Sarkar, P. K. Jana, and B. K. Chaudhuri, "Colossal internal barrier layer capacitance effect in polycrystalline copper (II) oxide," Applied Physics Letters, vol. 92, no. 2, article 022905, 2008.

[6] H. Ogihara, C. A. Randal, and S. Troiler-McKinstry, "Highenergy density capacitors utilizing 0.7 BaTiO3-0.3 $\mathrm{BiScO} 3-$ Ceramics," Journal of the American Ceramic Society, vol. 92, no. 8, pp. 1719-1724, 2009.

[7] C. C. Homes, T. Vogt, S. M. Shapiro, S. Wakimoto, and A. P. Ramirez, "Optical response of high-dielectric-constant perovskite-related oxide," Science, vol. 293, no. 5530, pp. 673-676, 2001.

[8] S. Krohns, P. Lunkenheimer, S. Meissner et al., "The route to resource-efficient novel materials," Nature Materials, vol. 10, no. 12, pp. 899-901, 2011.

[9] J. Dumas, C. Schlenker, J. Marcus, and R. Buder, "Nonlinear Conductivity and Noise in the Quasi One-Dimensional Blue BronzeK0.30MoO3," Physical Review Letters, vol. 50, no. 10, pp. 757-760, 1983.

[10] Y. Q. Wu, X. Zhao, J. L. Zhang, W. B. Su, and J. Liu, "Huge lowfrequency dielectric response of (Nb,In)-doped TiO2ceramics," Applied Physics Letters, vol. 107, no. 24, article 242904, 2015.

[11] J. L. Li, F. Li, Y. Y. Zhuang et al., "Microstructure and dielectric properties of $(\mathrm{Nb}+\mathrm{In})$ co-doped rutile TiO2ceramics," Journal of Applied Physics, vol. 116, no. 7, article 074105, 2014.

[12] C. J. Raj, G. Paramesh, B. S. Prakash, K. R. S. P. Meher, and K. B. R. Varma, "Origin of giant dielectric constant and conductivity behavior in $\mathrm{Zn} 1-\mathrm{xMgxO}(0 \leq \mathrm{x} \leq 0.1)$ ceramics," Materials Research Bulletin, vol. 74, pp. 1-8, 2016.

[13] D. Huang, Z. Liu, Y. Li, and Y. Liu, "Colossal permittivity and dielectric relaxation of ( $\mathrm{Li}, \mathrm{In}) \mathrm{Co}$-doped $\mathrm{ZnO}$ ceramics," Journal of Alloys and Compounds, vol. 698, pp. 200-206, 2017.

[14] X. H. Li, L. Xu, L. Liu et al., "High pressure treated $\mathrm{ZnO}$ ceramics towards giant dielectric constants," Journal of Materials Chemistry A, vol. 2, no. 39, pp. 16740-16745, 2014.

[15] C. Luo, L. P. Ho, F. Azad et al., "Sb-related defects in Sb-doped $\mathrm{ZnO}$ thin film grown by pulsed laser deposition," Journal of Applied Physics, vol. 123, no. 16, p. 161525, 2018.

[16] M. Pal, U. Pal, J. Jiménez, and F. Pérez-Rodríguez, "Effects of crystallization and dopant concentration on the emission behavior of TiO2:Eu nanophosphors," Nanoscale Research Letters, vol. 7, no. 1, p. 1, 2012.

[17] V. Kumar, N. Singh, R. Mehra, A. Kapoor, L. Purohit, and H. Swart, "Role of film thickness on the properties of $\mathrm{ZnO}$ thin films grown by sol-gel method," Thin Solid Films, vol. 539, pp. 161-165, 2013.

[18] R. R. Hake, "UPPER-CRITICAL-FIELD LIMITS FOR BULK TYPE-II SUPERCONDUCTORS," Applied Physics Letters, vol. 10, no. 6, pp. 189-192, 1967.

[19] N. Felemban, O. M. Aldossary, and V. E. Lembessis, "Atomic mirrors for a $\Lambda$-type three-level atom," J Phys B At Mol Opt Phys, vol. 47, no. 18, article 185005, 2014.
[20] M. Acosta-Humánez, L. Montes-Vides, and O. Almanza-Montero, "Sol-gel synthesis of zinc oxide nanoparticle at three different temperatures and its characterization via XRD, IR and EPR,” Dyna (Medellin), vol. 83, no. 195, pp. 224-228, 2016.

[21] F. Mikailzade, H. Türkan, F. Önal, M. Zarbali, A. Göktaş, and A. Tumbul, "Structural and magnetic properties of polycrystalline $\mathrm{Zn1-xMnxO}$ films synthesized on glass and p-type Si substrates using Sol-Gel technique," Applied Physics A: Materials Science \& Processing, vol. 127, no. 6 article 408, 2021.

[22] W. S. Ni, Y. J. Lin, C. J. Liu, Y. W. Yang, and L. Horng, "Luminescence, structural and ferromagnetic properties of $\mathrm{Zn} 1$ -xMnxSy films for different manganese contents," Journal of Alloys and Compounds, vol. 556, pp. 178-181, 2013.

[23] X. Guo, Y. Liu, Y. Yang et al., "Effective visible-light excited charge separation in all-solid-state Ag bridged BiVO4/ ZnIn2S4 core-shell structure Z-scheme nanocomposites for boosting photocatalytic organics degradation," Journal of Alloys and Compounds, vol. 887, article 161389, 2021.

[24] S. Thakur, N. Sharma, A. Varkia, and J. Kumar, "Structural and optical properties of copper doped $\mathrm{ZnO}$ nanoparticles and thin films," Advances in Applied Science Research, vol. 5, no. 4, p. 18, 2014.

[25] A. Tumbul, A. Göktaş, M. Z. Zarbali, and F. Aslan, "Structural, morphological and optical properties of the vacuum-free processed CZTS thin film absorbers," Mater Res Express, vol. 5, no. 6, article 066408, 2018.

[26] S. S. Kushvaha, M. S. Kumar, M. Maheshwari, A. K. Shukla, P. Pal, and K. K. Maurya, "Structural and electronic properties of epitaxial GaN layer grown on sapphire (0001) using laser molecular beam epitaxy," Mater. Res. Exp., vol. 1, no. 3, article 035903, 2014.

[27] A. Goktas, F. Aslan, and A. Tumbul, "Nanostructured Cudoped $\mathrm{ZnS}$ polycrystalline thin films produced by a wet chemical route: the influences of $\mathrm{Cu}$ doping and film thickness on the structural, optical and electrical properties," Journal of Sol-Gel Science and Technology, vol. 75, no. 1, pp. 45-53, 2015.

[28] J. Dai, Z. Suo, Z. Li, and S. Gao, "Effect of $\mathrm{Cu} / \mathrm{Al}$ doping on electronic structure and optical properties of $\mathrm{ZnO}$," Results in Physics, vol. 15, article 102649, 2019.

[29] R. Muccillo, E. N. S. Muccillo, and M. Kleitz, "Densification and enhancement of the grain boundary conductivity of gadolinium-doped barium cerate by ultra fast flash grain welding," Journal of the European Ceramic Society, vol. 32, no. 10, pp. 2311-2316, 2012.

[30] R. Muccillo, "Impedance spectroscopy analysis of zirconia:8 mol\% yttria solid electrolytes with graphite pore former," Journal of Materials Research, vol. 24, no. 5, pp. 1780-1784, 2009.

[31] A. S. Kavasoglu, N. Kavasoglu, and S. Oktik, "Simulation for capacitance correction from Nyquist plot of complex impedance- voltage characteristics," Electronics Letters, vol. 52, no. 6, pp. 990-996, 2008.

[32] M. Younas, L. L. Zou, M. S. S. C. Nadeem et al., "Impedance analysis of secondary phases in a Co-implanted $\mathrm{ZnO}$ single crystal," Physical Chemistry Chemical Physics, vol. 16, no. 30, pp. 16030-16038, 2014.

[33] T. Pralhad and K. Rajendrakumar, "Study of freeze-dried quercetin-cyclodextrin binary systems by DSC, FT-IR, X-ray diffraction and SEM analysis," Journal of pharmaceutical and biomedical analysis, vol. 34, no. 2, p. 333, 2004. 